\title{
Crescimento e sobrevivência de castanheira (Bertholletia excelsa Bonpl., Lecythidaceae) plantada em diferentes condições de luminosidade após seis anos de plantio na região do rio Trombetas, Oriximiná, Pará \\ Performance and survival of Brazil nut tree (Bertholletia excelsa Bonpl., Lecythidaceae), in different light conditions after six years to planting, in Trombetas River region, Oriximiná, Pará, Brazil
}

\author{
Ricardo Scoles', Gilmar Nicolau Klein", Rogério Gribel"II \\ 'Universidade Federal do Oeste do Pará. Santarém, Pará, Brasil \\ "Instituto Chico Mendes de Conservação da Biodiversidade. Presidente Figueiredo, Amazonas, Brasil \\ IIIInstituto de Pesquisa do Jardim Botânico do Rio de Janeiro. Rio de Janeiro, Rio de Janeiro, Brasil
}

Resumo: Este estudo avaliou o desempenho e a sobrevivência da castanheira (Bertholletia excelsa Bonpl., Lecythidaceae) em três ambientes com diferentes condições de luz em plantios experimentais localizados na região do rio Trombetas (Oriximiná, Pará). Três tratamentos ambientais de exposição à luz: roçados de mandioca abandonados (100\% de abertura de dossel), capoeiras jovens (20-80\%) e sub-bosque de castanhais (< 10\%), com quatro repetições, foram utilizados para o desenvolvimento da pesquisa. Por seis anos, mediram-se as plantas (altura, diâmetro do caule) e registraram-se os episódios de mortalidade e rebrotação. As plantas de castanheira no roçado tiveram um crescimento muito maior, em altura e diâmetro, que as dos outros dois tratamentos. O índice de sobrevivência das castanheiras plantadas variou conforme o tratamento adotado: 90\% (roçado), 77\% (capoeira) e 21\% (sub-bosque de castanhal). A capacidade de rebrotação das plantas de castanheira foi altíssima no tratamento de roçado, recuperando-se de forma significativa após um ano da perturbação severa causada por fogo e com surgimento majoritário de mais de um caule. Conclui-se que a castanheira é uma árvore fortemente dependente de luz para o seu desempenho juvenil, com alta sobrevivência em condições de exposição à luz e com alta capacidade de rebrotação após perturbação por fogo.

Palavras-chave: Dendrometria. Silvicultura. Luz. Rebrotação. Fogo.

\begin{abstract}
This study assesses the performance and survival of Brazil nut tree (Bertholletia excelsa Bonpl., Lecythidaceae) in different conditions and levels of ambient light: within experimental plantations in the Trombetas River region (Oriximiná, Pará). Three natural incident light treatments: manioc field (100\% canopy removal), young secondary forest (20-80\% canopy cover) and the understory of a Brazil nut stands ( $<10 \%$ canopy opening), with four replicates, were used in the experiment. For six years, plant height and stem diameter were measured, and mortality and regrowth were recorded. The Brazil nut plants of the manioc field had greatest growth (height and diameter) than other two treatments. The survival of plants rate varied according to the treatment: manioc field (90\%), young secondary forest (77\%) and understory of the forest (21\%). The regrowth capacity was very high in the manioc field, recovering strongly after incidents of fire and with the majority exhibiting the regeneration of more than one emergent stalk. Overall we report that the performance of juvenile Brazil nut trees is dependent on ambient light, with higher survival in conditions of high light exposure and a higher level of regrowth after disturbance by fire.
\end{abstract}

Keywords: Dendrometry. Silviculture. Light. Regrowth. Fire.

SCOLES, R., G. N. KLEIN \& R. GRIBEL, 2014. Crescimento e sobrevivência de castanheira (Bertholletia excelsa Bonpl., Lecythidaceae) plantada em diferentes condições de luminosidade após seis anos de plantio na região do rio Trombetas, Oriximiná, Pará. Boletim do Museu Paraense Emílio Goeldi. Ciências Naturais 9(2): 321-336.

Autor para correspondência: Ricardo Scoles. Universidade Federal do Oeste do Pará. Av. Vera Paz, s/n - Salé. Santarém, PA, Brasil. CEP 68135-110 (ricardscoles@yahoo.es).

Recebido em 30/10/2013

Aprovado em 29/07/2014

Responsabilidade Editorial: Toby A. Gardner

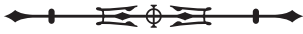




\section{INTRODUÇÃO}

A castanheira (Bertholletia excelsa Bonpl.), da família Lecythidaceae, é uma árvore emergente típica de florestas tropicais úmidas de terra firme. A ocorrência natural da espécie limita-se à bacia hidrográfica dos rios Amazonas e Orenoco, distribuindo-se de forma descontínua entre as latitudes $5^{\circ} \mathrm{Se} 14^{\circ} \mathrm{N}$, com pluviometria anual entre $1.400 \mathrm{e}$ $2.800 \mathrm{~mm}$, tolerando períodos de estiagem $(<60 \mathrm{~mm}$ por mês) durante dois a cinco meses (Müller et al., 1980; Mori \& Prance, 1990). Nas florestas, B. excelsa é uma espécie social, com tendência a formar adensamentos naturais (castanhais) contendo entre 5-20 indivíduos por hectare, intercalados com áreas de baixa densidade (Mori \& Prance, 1990).

Segundo o Instituto Brasileiro de Geografia e Estatística (IBGE, 2011), as sementes são o segundo produto extrativo não madeireiro em importância econômica na Amazônia brasileira, perdendo apenas para o açaí. Nos estados do Acre e Amazonas e no oeste do Pará, a castanha-do-pará, também denominada de castanha-do-brasil, ocupa o primeiro lugar (IDESP, 2011; IBGE, 2011). Embora a coleta de castanha seja uma importante fonte de renda para milhares de comunidades rurais amazônicas, isso não exclui que parte da safra seja destinada para consumo familiar. A produção da castanha é obtida, quase exclusivamente, de atividade extrativa florestal, sendo as plantações pouco significativas em termos quantitativos (Clay, 1997; Pereira et al., 2010).

A castanheira pode ser considerada como uma espécie clímax exigente de luz (Swaine \& Whitmore, 1988), por ser uma espécie florestal de grande porte, dominante, emergente e longeva, cuja fase juvenil depende de luz para seu crescimento vertical (Salomão, 1991; Mori, 1992; Peña-Claros et al., 2002; Scoles et al., 2011). A castanheira é uma árvore com altas taxas de sobrevivência, exceto nas etapas iniciais da vida, quando a plântula possui o hipocotiledone, reserva nutricional e potencial recurso alimentar para cutias (Dasyprocta spp.) e outros mamíferos terrestres (Oliveira, 2000; Ortiz, 2002; Zuidema, 2003). O índice de sobrevivência das plântulas (ou mudas) de castanheira se aproxima de 100\% quando o hipocotiledone desaparece ou já se lignificou, o que ocorre normalmente quando a planta tem altura superior a 70 cm (Zuidema \& Boot, 2002; Scoles et al., 2011).

A distribuição desigual da espécie nas diferentes regiões da Amazônia, as dificuldades de acesso a alguns castanhais produtivos (Scoles \& Gribel, 2012; Ricardo Scoles et al., comunicação pessoal), a degradação biológica de populações de castanheira localizadas em áreas de expansão agropecuária nas margens das estradas (Bentes et al.,1988; Homma et al., 2000; Ricardo Scoles et al., comunicação pessoal) e o baixo controle da produção característico dos produtos extrativistas pouco ou nada manejados (Homma, 1993; Anderson, 1994; Clement, 2006) justificam a promoção de práticas de plantios de enriquecimento de castanheira em áreas próximas às comunidades humanas. Nessas áreas, como consequência de práticas tradicionais de agricultura itinerante ('shifting cultivation'), predominam ecossistemas antropizados em processo de regeneração secundária (capoeiras), com média ou alta exposição à luz solar.

Em várias regiões da Amazônia foram feitos plantios experimentais de castanheira em diferentes condições de exposição de luz, evidenciando-se que, em geral, o desempenho da castanheira é maior em condições de alta luminosidade (Kainer et al., 1998; Myers et al., 2000; Peña-Claros et al., 2002; Scoles et al., 2011). De igual forma, o monitoramento de diversas plantações experimentais a pleno sol revelaram alta taxa de crescimento da castanheira (Fernandes \& Alencar, 1993; Yared et al., 1993; Vieira et al., 1998; Tonini et al., 2005). Além disso, várias pesquisas evidenciaram que os castanhais com maior influência humana (manejados e/ou muito frequentados) apresentavam uma taxa de regeneração da castanheira mais alta que aqueles localizados em florestas primárias (Pereira, 1994; Paiva et al., 2011; Scoles \& Gribel, 2011; Scoles, 2012; Ribeiro et al., 2014), seja pela maior disponibilidade de luz, seja pelas maiores possibilidades de dispersão e recrutamento, devido a uma maior perambulação nessas áreas dos principais dispersores involuntários das sementes de castanha (seres humanos e cutias, principalmente). De fato, pesquisas revelam como as cutias, uma vez saciadas, se houver oportunidade, costumam 
esconder as sementes excedentes em áreas de capoeira, por terem estas um sub-bosque mais denso (Cotta et al., 2008; Paiva et al., 2011; Tuck Haugaasen et al., 2010, 2012).

Numerosos estudos em áreas experimentais de silvicultura revelam que a castanheira é uma espécie promissora para reflorestamento de áreas degradadas e/ou desflorestadas, devido às altas taxas de sobrevivência das mudas plantadas com mais de um metro de altura, sua tolerância a solos degradados, alto desempenho em condições de alta luminosidade e resistência a secas prolongadas (Fernandes \& Alencar, 1993; Yared et al., 1993; Salomão et al., 2006; Souza et al., 2008; Costa et al., 2009). Além disso, existem indícios de que a castanheira tem alta capacidade de rebrotação após episódios de perturbação por fogo (Balée \& Campbell, 1990; Paiva et al., 2011; Scoles et al., 2011).

A finalidade deste trabalho é testar o desempenho de mudas de castanheira plantadas em diferentes tratamentos de intensidade de luz, após seis anos de sua plantação. Este trabalho é singular e se diferencia de outros estudos experimentais de crescimento da castanheira por dois motivos: (1) comparação de três tratamentos ambientais (roçado de mandioca abandonado, capoeira jovem e sub-bosque de castanhais), os principais locais onde ocorre a regeneração natural dessa espécie e (2) áreas experimentais sem controle artificial das mudas de castanheira, o que se aproxima melhor das condições ambientais naturais em que as plantas se regeneram, embora essa situação possa gerar maiores riscos de as plantações sofrerem perturbações externas.

\section{MATERIAL E MÉTODOS}

\section{ÁREA DE ESTUDO}

As plantações experimentais de castanheira estudadas situam-se na parte mais setentrional da Floresta Nacional de Saracá-Taquera, na região do rio Trombetas, município de Oriximiná, oeste do estado do Pará, em uma área de uso dos moradores da comunidade quilombola de Tapagem (Figura 1). A bacia do rio Trombetas, especialmente no seu trecho alto e médio, abriga grandes extensões florestais com abundância de castanhais, muitos destes localizados em áreas de proteção pública ou de titulação quilombola (Acevedo Marin \& Castro, 1998; Scoles \& Gribel, 2012).

Considerando os dados climáticos da estação meteorológica de Porto Trombetas ( $1^{\circ} 46^{\prime} \mathrm{S}, 56^{\circ} 37^{\prime} \mathrm{W}$ ), o clima da região de estudo é equatorial e úmido, com precipitações médias anuais que geralmente superam os $2.000 \mathrm{~mm}$, temperaturas médias anuais elevadas (entre 25 e $26^{\circ} \mathrm{C}$ ), com pouca amplitude diária e sazonal, e umidade relativa do ar superior a 75\%. Conforme ocorre em toda a bacia amazônica, a região tem períodos distintos de pluviosidade, com uma estação chuvosa (de janeiro a maio) e uma estação 'seca' ou menos chuvosa (precipitação mensal < $100 \mathrm{~mm}$, de julho a novembro). De igual forma, a insolação também apresenta sazonalidade, sendo os meses de agosto, setembro e outubro os de maior exposição solar, com mais de 200 horas por mês (IBAMA/MRN, 2001; INPE, 2014). Os plantios situam-se em áreas de terras baixas com superfície ondulada, entre 50 e 125 metros de altitude, com solos classificados de neossolos quartzarênicos, em geral pouco evoluídos e pobres em nutrientes (IBAMA/MRN, 2001).

\section{DESENHO DA PESQUISA}

A pesquisa foi autorizada pelo Instituto Chico Mendes de Conservação da Biodiversidade (ICMBIO), emitida pelo Sistema de Autorização e Informação em Biodiversidade (SISBIO) e expressa pela coordenação da Comunidade Quilombola de Tapagem.

O número de mudas plantadas foi de 144 , distribuídas em 12 parcelas de quatro repetições e três tratamentos diferenciados pelas condições ambientais de luz (Scoles et al., 2011): 1) áreas de lavoura de mandioca (Manihot esculenta), com praticamente $100 \%$ de entrada de luz; 2) áreas de capoeira baixa (entre dois a cinco anos de pousio), com abertura inicial do dossel variável entre 20-80\%; 3) sub-bosque de castanhais com alto sombreamento ( $<10 \%$ de entrada de luz). As parcelas dos tratamentos de roçado e capoeira localizam-se muito 
próximas das residências dos comunitários, enquanto as de sub-bosque de castanhais situam-se na margem direita do igarapé Saco das Armas, a cerca de 3 km de distância do centro comunitário de Tapagem (Figura 1).
Nas parcelas de roçado, as mudas foram plantadas em área limpa, com percentagem de luz incidente de praticamente 100\%. Para manter essa situação, foi preciso realizar atividades periódicas de manutenção e limpeza ao

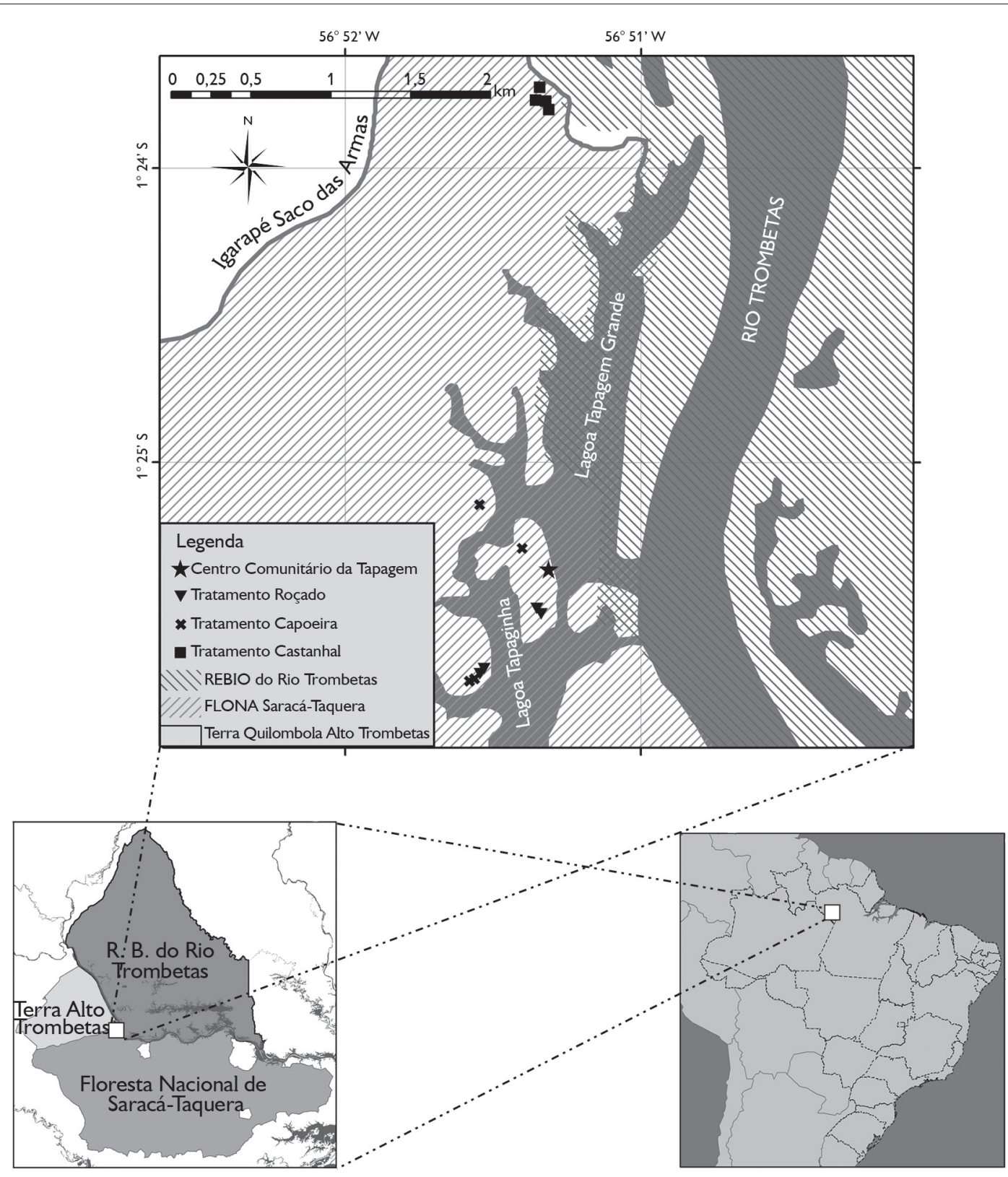

Figura 1. Localização das plantações experimentais de mudas de Bertholletia excelsa na Floresta Nacional de Saracá-Taquera, rio Trombetas, Oriximiná, Pará.

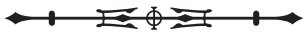


redor das mudas a cada dois meses durante os primeiros dois anos, com o objetivo de evitar sombreamentos na parte apical da planta. Após esse período, as tarefas de manutenção foram feitas uma vez por ano. Nos outros dois tratamentos, as únicas manipulações realizadas foram a limpeza ao redor da muda e o corte de lianas.

Para cada tratamento houve quatro parcelas ou repetição, desenhando-se uma grade de $20 \times 30$ m, onde foram plantadas 12 mudas de castanheira em espaçamentos de $10 \times 10 \mathrm{~m}$, em covas de $40 \mathrm{~cm}$ de profundidade e com uso inicial de adubo orgânico. Ao todo, em cada tratamento foram colocadas 48 mudas. As mudas foram produzidas no viveiro do Porto de Trombetas (Oriximiná, Pará) e doadas pelo projeto Banco de Germoplasma de Castanheira (Instituto Nacional de Pesquisas da Amazônia, Mineração Rio do Norte).

A procedência geográfica das sementes para produção das mudas foi diversificada e distribuída de forma paritária nos três tratamentos (Scoles et al., 2011). As mudas selecionadas tinham uma altura entre $80-120 \mathrm{~cm}$, com média de 107,6 \pm 15,8 cm e um diâmetro médio na base do colo de 7,9 $\pm 2,1 \mathrm{~mm}$. A idade das mudas plantadas em março de 2007, calculada a partir da data de repicagem, variou entre os 11 e 40 meses de idade (Scoles et al., 2011).

Nesta pesquisa, diferentemente da maioria dos experimentos silviculturais conhecidos, os plantios não foram realizados em áreas experimentais com acesso restrito, mas em áreas de uso comunitário. Isso foi propositalmente planejado e previamente decidido, pois os ambientes onde foram colocadas as mudas (roçados abandonados, capoeiras jovens e sub-bosques de castanhais) representavam melhor as condições onde as plantas jovens naturalmente se desenvolvem, apesar do maior risco de sofrerem perturbações artificiais. No segundo semestre de 2009, duas parcelas do tratamento de roçado foram atingidas acidentalmente pelo fogo proveniente de um roçado vizinho. A totalidade das mudas nessas duas parcelas, que estavam com apreciável crescimento após dois anos de plantação (Scoles et al., 2011), foi queimada, mas ainda assim a maioria delas sobreviveu ao episódio severo de perturbação.
Para coleta de dados morfométricos e observacionais, realizaram-se visitas anuais nas áreas experimentais (março de 2007 a 2013), com a finalidade de mensurar altura e diâmetro do colo. Quando a muda alcançou 1,75 m de altura, mediu-se também o diâmetro à altura do peito (DAP), que apresentou o valor de 1,3 m do solo. As alterações e/ou perturbações observadas na muda, como secagem, cortes, queimas e rebrotação, eram anotadas, assim como os episódios de morte.

\section{AMOSTRAS E ANÁLISE DE SOLO}

Doze amostras compostas de solo foram coletadas, uma para cada parcela experimental de 12 mudas (quatro repetições, três tratamentos). A camada de solo retirada era a mesma da cova da plantação das mudas, em uma profundidade que variava entre $0-40 \mathrm{~cm}$. As análises físicas (textura) e químicas ( $\mathrm{pH}$, carbono, nutrientes) das amostras do solo foram realizadas no Laboratório Temático de Plantas e Solos do Instituto Nacional de Pesquisas da Amazônia (Manaus, Amazonas). A metodologia usada seguiu as normas recomendadas pela Empresa Brasileira de Pesquisa Agropecuária (EMBRAPA, 1997, 1999, 2006).

\section{ANÁLISES DE DADOS}

O índice de sobrevivência das mudas foi calculado por meio do percentual entre número de plantas sobreviventes em relação ao número total de mudas plantadas. A comparação da sobrevivência por tratamentos foi testada com Qui-Quadrado $\left(\chi^{2}\right)$.

O desempenho das mudas ao longo dos seis anos de monitoramento foi calculado através do Incremento Corrente Médio em altura (ICM ${ }_{\mathrm{h}}$ ), Incremento Corrente Médio em diâmetro (ICM $\left.{ }_{\mathrm{d}}\right)$, Incremento Médio Anual em altura (IMA $A_{h}$ e Incremento Corrente Médio Anual em diâmetro $\left(\mathrm{IMA}_{\mathrm{d}}\right)$. O ICM $\mathrm{I}_{\mathrm{h}}$ e ICM foram calculados através da diferença entre a altura e diâmetro médio obtidos, respectivamente, a partir das medições finais e iniciais (março de 2013 e de 2007). Já o ICM e IMA foram calculados da mesma forma, após o que se dividiu a diferença calculada pelo número de intervalos do monitoramento (seis anos). 
Os índices de desempenho das mudas plantadas $\left(\right.$ ICM $_{h}$, IMA,$I C M_{d}$ e IMA ) e as propriedades físico-químicas do solo dos três tratamentos foram comparados por meio de dois tipos de análise de comparação de médias: 1) paramétrico (ANOVA e teste 't' pareado), para amostras distribuídas com normalidade, e 2) não paramétrico (teste de KrustalWallis ou teste de Mann-Whitney), quando as amostras não tinham uma distribuição normal. Para analisar normalidade da distribuição estatística das amostras, usou-se o teste de Lilliefors, com nível de significância de 0,05 (Lilliefors, 1967).

\section{RESULTADOS}

\section{TEXTURA E PROPRIEDADES QUÍMICAS DO SOLO}

Os solos das parcelas de roçado (areia, 56,7 \pm 12,6\%; argila, $28,5 \pm 12,0 \%$; silte, $14,8 \pm 3,8 \%$ ) e de capoeira (areia, 39,2 \pm 7,0\%; argila, 33,0 \pm 4,0\%; silte, 27,8 \pm
6,7\%) tiveram uma maior proporção de textura arenosa. Os solos das parcelas de sub-bosque de castanhais tiveram uma textura ligeiramente mais argilosa (areia, $32,8 \pm 6,1 \%$; argila, 42,0 $\pm 10,6 \%$; silte, 25,2 $\pm 9,4 \%$ ), embora as diferenças entre tratamentos não tenham sido estatisticamente significativas (areia, $p=0,199$; silte, $p=$ 0,05; argila, $p=0,064$, teste de Krustal-Wallis).

Para a maioria de variáveis químicas estudadas $(\mathrm{pH}$, matéria orgânica, Capacidade de Troca de Cátions CTC, nutrientes) não houve diferenças significativas entre tratamentos; ainda assim, na parcela de sub-bosque de castanhal, as concentrações de cálcio e manganês extraídos foram significativamente mais baixas do que nos outros dois tratamentos (Tabela 1).

\section{DESEMPENHO DAS MUDAS}

Das 144 mudas plantadas (Tabela 2), 54 (37,5\%) morreram no curso dos seis anos de monitoramento. Das 90

Tabela 1. Resultados das análises estatísticas (teste de Krustal-Wallis (K-W); nível de significância: $\alpha=0,05$ ) das propriedades químicas dos solos (valores médios \pm desvio padrão das variáveis) por tratamento nos plantios experimentais de Trombetas. Quando $p \leq 0,05$, foram feitas comparações múltiplas por pares mediante procedimento de Dunn. As letras a e b em sobrescrito mostram diferenças significativas entre tratamentos, com nível de significância corrigido de Bonferroni de 0,0167. Fonte: Scoles et al. (2011).

\begin{tabular}{|c|c|c|c|c|}
\hline Variável & Roçado & Capoeira & Castanhal & Teste K-W (p) \\
\hline $\mathrm{pH}$ em $\mathrm{H}_{2} \mathrm{O}$ & $3,94 \pm 0,38$ & $4,08 \pm 0,32$ & $3,93 \pm 0,08$ & 0,664 \\
\hline Carbono $\left(\mathrm{mg} \mathrm{kg}^{-1}\right)$ & $11,74 \pm 3,72$ & $10,60 \pm 2,49$ & $13,91 \pm 2,33$ & 0,174 \\
\hline Nitrogênio $(m g ~ k g-1)$ & $0,93 \pm 0,21$ & $0,90 \pm 0,21$ & $1,24 \pm 0,22$ & 0,138 \\
\hline $\mathrm{C} / \mathrm{N}$ & $12,42 \pm 1,38$ & $11,80 \pm 0,62$ & $11,24 \pm 1,16$ & 0,298 \\
\hline Matéria orgânica (\%) & $2,02 \pm 0,64$ & $1,83 \pm 0,43$ & $2,40 \pm 0,40$ & 0,196 \\
\hline Fósforo $\left(\mathrm{mg} \mathrm{kg}^{-1}\right)$ & $14,60 \pm 6,98$ & $29,22 \pm 46,45$ & $12,42 \pm 2,15$ & 0,551 \\
\hline Cálcio $\left(\mathrm{mg} \mathrm{kg}^{-1}\right)$ & $134,38 \pm 91,29^{a}$ & $133,00 \pm 61,11^{\mathrm{a}}$ & $27,38 \pm 10,56^{b}$ & 0,025 \\
\hline Magnésio $\left(\mathrm{mg} \mathrm{kg}^{-1}\right)$ & $29,88 \pm 24,83$ & $23,63 \pm 6,17$ & $19,88 \pm 3,68$ & 0,694 \\
\hline Potássio $(m g$ kg-1) & $33,13 \pm 20,41$ & $27,00 \pm 6,92$ & $34,25 \pm 2,40$ & 0,232 \\
\hline Alumínio $\left(\mathrm{cmol}_{\mathrm{c}} \mathrm{kg}^{-1}\right)$ & $0,92 \pm 0,58$ & $0,68 \pm 0,34$ & $1,32 \pm 0,32$ & 0,138 \\
\hline CTC $_{t}$ efetiva $\left(\mathrm{cmol}_{\mathrm{c}} \mathrm{kg}^{-1}\right)$ & $1,93 \pm 0,97$ & $1,61 \pm 0,19$ & $1,71 \pm 0,38$ & 0,94 \\
\hline Saturação por bases (V\%) & $53,17 \pm 21,92$ & $58,69 \pm 19,66$ & $22,95 \pm 3,52$ & 0,058 \\
\hline Saturação por alumínio (m\%) & $46,83 \pm 21,92$ & $41,31 \pm 19,66$ & $77,05 \pm 3,52$ & 0,058 \\
\hline Ferro $\left(\mathrm{mg} \mathrm{kg}^{-1}\right)$ & $147,75 \pm 21,72$ & $117,00 \pm 42,15$ & $159,00 \pm 39,27$ & 0,491 \\
\hline Manganês $\left(\mathrm{mg} \mathrm{kg}^{-1}\right)$ & $10,15 \pm 6,99^{a}$ & $15,08 \pm 7,04^{a}$ & $1,55 \pm 0,39^{b}$ & 0,018 \\
\hline Zinco $\left(\mathrm{mg} \mathrm{kg}^{-1}\right)$ & $0,63 \pm 0,30$ & $0,73 \pm 0,56$ & $0,93 \pm 0,34$ & 0,569 \\
\hline
\end{tabular}

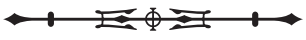


Tabela 2. Número de mudas de Bertholletia excelsa por tratamento e incidências após seis anos de plantio.

\begin{tabular}{c|c|c|c|c}
\hline Tratamento & Normais & Rebrotos & Mortas & Total \\
\hline Roçado & 21 & 22 & 5 & 48 \\
\hline Capoeira & 17 & 20 & 11 & 48 \\
\hline Castanhal & 5 & 5 & 38 & 48 \\
\hline Total & 43 & 47 & 54 & 144 \\
\hline
\end{tabular}

sobreviventes, 43 (49\%) mudas estavam sem alterações significativas na sua estrutura aérea e foram consideradas 'normais' neste estudo. As 47 (51\%) restantes tinham sofrido algum processo de alteração e/ou perturbação externa com interrupção temporal do crescimento e posterior rebrotação.

\section{Sobrevivência}

O índice de sobrevivência das mudas da castanheira após seis anos da plantação variou conforme tratamento: $90 \%$ roçado, $77 \%$ capoeira e $21 \%$ sub-bosque de castanhais. As diferenças foram significativas entre sub-bosque de castanhais e os outros dois tratamentos $\left(\chi^{2}, p<0,001\right)$. Nessas parcelas, a mortalidade de mudas se elevou no intervalo entre o segundo e o terceiro ano de plantio (21 mortes, 47,7\% das mudas plantadas), o que reduziu o índice de sobrevivência de 90\% para 46\% (Figura 2).

\section{Rebrotação}

Ao longo de seis anos, foram observados 46 casos de rebrotação considerando todos os plantios (51,1\% das mudas vivas). As frequências de rebrota não variaram significativamente com o tratamento $\left(\chi^{2}, p=0,96\right)$, sendo maiores na capoeira ( $54,1 \%$ das mudas vivas), seguida do tratamento de sub-bosque de castanhais $(50,0 \%)$ e roçado (48,8\%). Nas parcelas de roçado e capoeira, as causas das alterações fisiológicas e morfológicas, que desencadearam o fenômeno de rebrotação, foram majoritariamente provocadas pela ação humana. Destaca-se que as mudas de duas parcelas de roçado sofreram queimaduras severas por fogo entre o segundo e o terceiro ano, mas somente duas morreram após essa perturbação. A maioria delas (90,5\% das mudas) rebrotou e cresceu novamente com vigor a partir do quarto

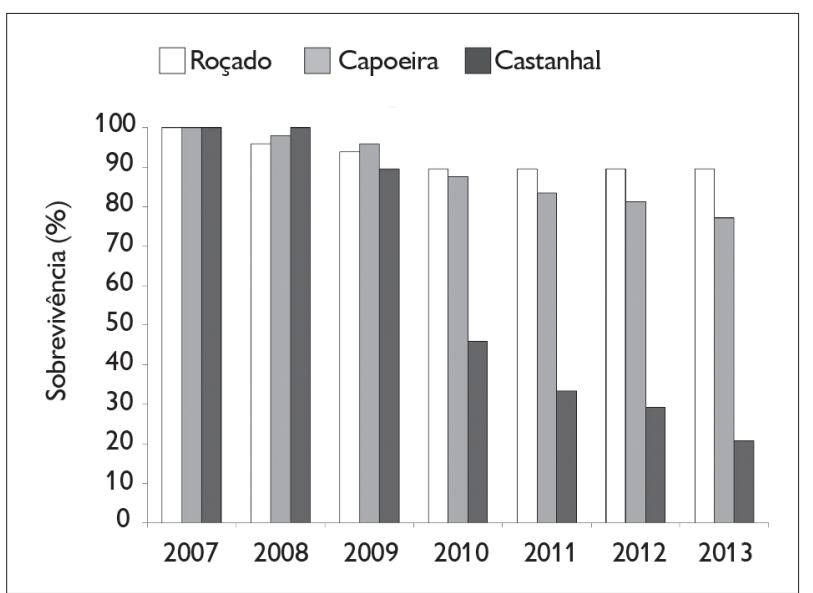

Figura 2. Índices de sobrevivência das mudas de Bertholletia excelsa por tratamento e ano nos plantios experimentais de Trombetas.

ano da plantação (um ano e meio após a perturbação) (Figuras 3 e 4). Entre as mudas rebrotadas após o episódio de fogo, observou-se majoritariamente rebrotação com formação de mais de um caule ( $n=15,79 \%$ dos casos): cinco rebrotaram com dois caules, três com três caules, duas com quatro, quatro com cinco e uma com oito caules.

$O$ crescimento das mudas queimadas foi comparativamente mais alto após o período de perturbação (2010-2013) do que nos dois anos iniciais da plantação (2007-2009). Entre 2010 e 2013, o IMA foi de 102,2 \pm 46,5 cm (máximo de $170 \mathrm{~cm}$; mínimo de $0 \mathrm{~cm}$ ), mediante IMA de 62,3 \pm 38,6 cm (máximo de 126,5 cm; mínimo de $0 \mathrm{~cm}$ ) entre 2007-2009, sendo as diferenças entre os dois períodos significativas (teste $t$ pareado, $\mathrm{p}=0,010$, $\alpha=0,05)$. De igual forma, no período 2010-2013, o IMA foi de 2,69 $\pm 2,68 \mathrm{~cm}$, mediante $\mathrm{IMA}_{\mathrm{d}}$ de 1,05 $\pm 1,08 \mathrm{~mm}$ entre 2007-2009. As diferenças entre ambos os períodos também foram significativas (teste $t$ pareado, $p=0,010$ ).

\section{Crescimento em altura e diâmetro}

As análises comparativas do crescimento em altura e diâmetro das plantas de castanheira realizaram-se com as plantas que não morreram nem sofreram rebrota ao longo dos seis anos de monitoramento, um total de 44 (30,6\%), sendo 22 de roçado, 17 de capoeira e cinco de sub-bosque de castanhais. 
No período monitorado (seis anos, 2007-2013), o crescimento em altura e diâmetro das plantas variou conforme o tratamento (Tabela 3; Figuras 3 e 4). No roçado, o IMA foi de 182,6 $\pm 33,5 \mathrm{~cm}$, cerca de oito vezes maior do que o verificado na parcela capoeira $\left(\right.$ IMA $_{h}$ $=21,6 \mathrm{~cm}$ ) e 39 vezes maior do que no sub-bosque de castanhais $\left(\mathrm{IMA}_{\mathrm{h}}=4,7 \mathrm{~cm}\right)$. As diferenças de crescimento em altura entre os três tratamentos foram significativas (ANOVA, $\left.F_{3,23}=211,38 ; p<0,0001\right)$. Nas comparações das médias por duplas mediante o teste de Tukey, as diferenças se mantiveram significativas entre o roçado e os outros dois tratamentos.

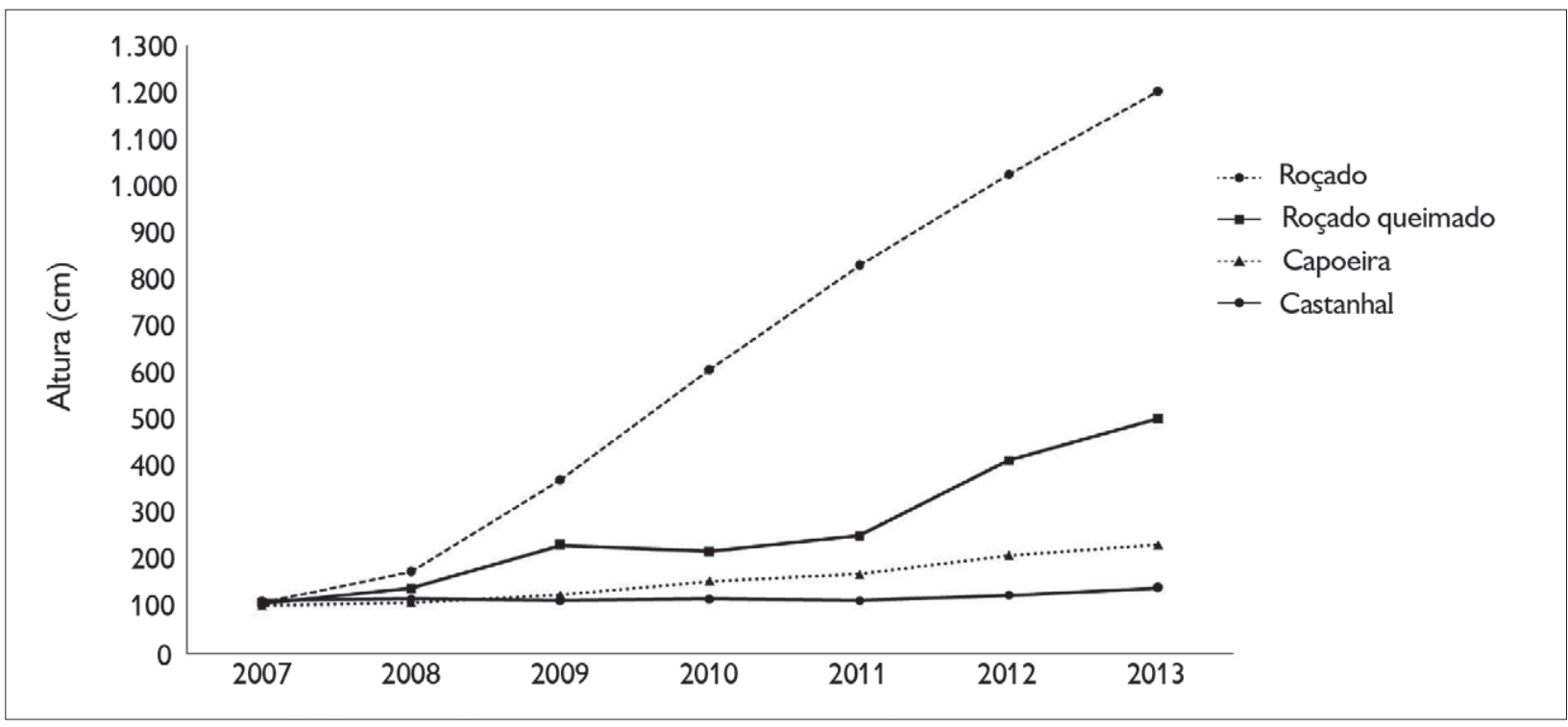

Figura 3. Dinâmica do IMA por ano e tratamento, incluindo as mudas de roçado queimadas nos plantios experimentais do rio Trombetas, Oriximiná, Pará.

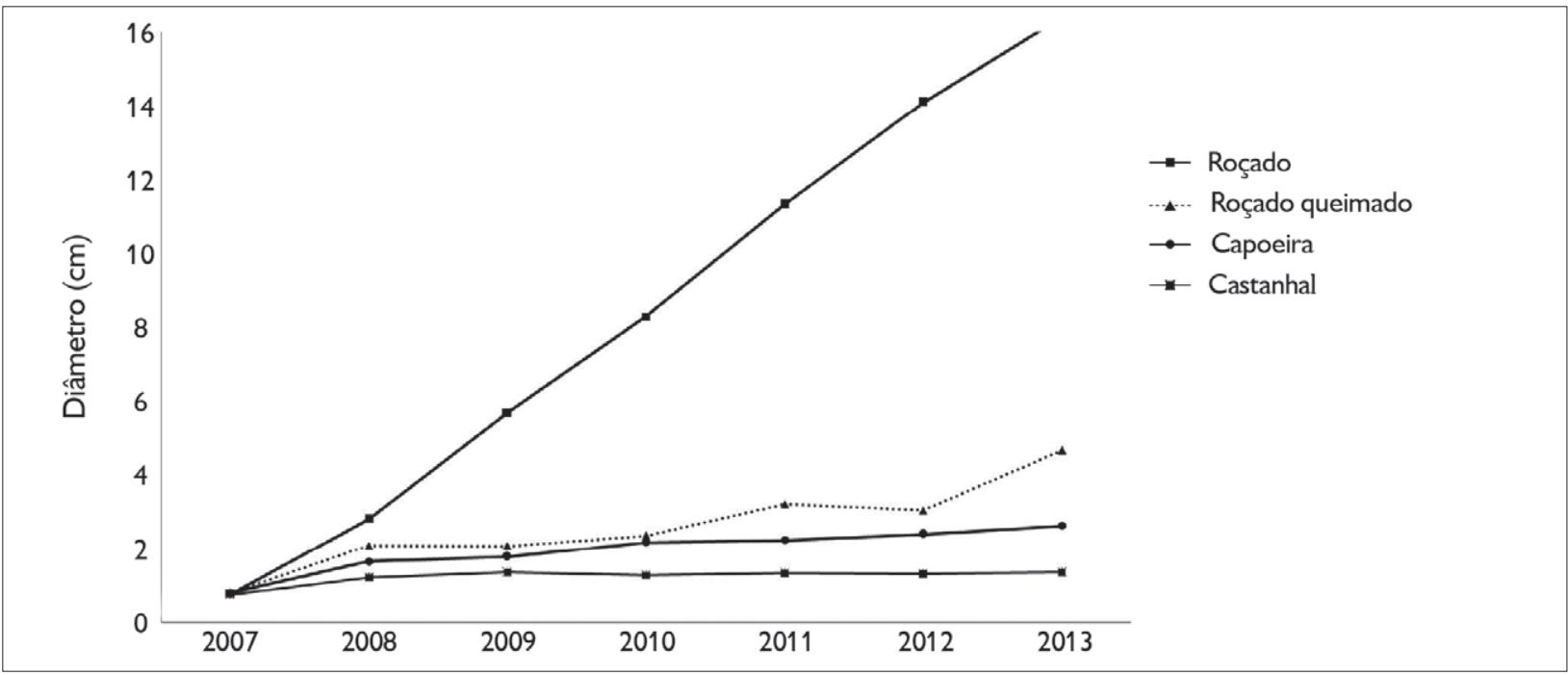

Figura 4. Dinâmica temporal de IMA por tratamento, incluindo as mudas de roçado queimadas nos plantios experimentais do rio Trombetas, Oriximiná, Pará.

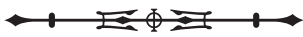


Em relação ao crescimento em diâmetro, as diferenças também foram significativas (ANOVA, $F_{3,23}=$ 113,22; $p<0,0001)$. No roçado, o IMA foi de 2,05 cm, quase sete vezes maior do que na capoeira $\left(\right.$ IMA $_{d}=$ 0,31 cm) e 20 vezes maior do que no sub-bosque de castanhais $\left(\mathrm{IMA}_{\mathrm{d}}=0,10 \mathrm{~cm}\right)$. Comparando as médias por duplas com o teste de Tukey, as diferenças unicamente deixaram de ser significativas entre as áreas de capoeira e castanhal (Tabela 3).
No tratamento de roçado, a dinâmica do crescimento em altura variou com o tempo, aumentando significativamente o seu desempenho no segundo e terceiro ano da plantação (Figuras 3 e 4, Tabela 4). Quando comparados os IMA por intervalos anuais com teste ANOVA, as diferenças foram significativamente mais altas no terceiro ano (IMA = $305,5 \mathrm{~cm}$ ) e mais baixas no primeiro (IMA $=65,2 \mathrm{~cm}$ ). Com respeito ao crescimento em diâmetro, o aumento mais pronunciado foi também no terceiro ano $\left(\mathrm{IMA}_{\mathrm{d}}=3,6 \mathrm{~cm}\right)$,

Tabela 3. Comparação do crescimento em altura e diâmetro das amostras de mudas nos três ambientes estudados após seis anos da plantação. As letras a e b em sobrescrito mostram diferenças significativas entre tratamentos.

\begin{tabular}{|c|c|c|c|c|c|c|}
\hline \multicolumn{7}{|c|}{ Crescimento em altura } \\
\hline & \multicolumn{3}{|c|}{ Incremento Corrente (seis anos) } & \multicolumn{3}{|c|}{ Incremento Médio Anual } \\
\hline Tratamento & $\begin{array}{l}\text { Média } \pm \text { d.p. } \\
\quad(\mathrm{cm})\end{array}$ & $\begin{array}{l}\text { Máximo } \\
(\mathrm{cm})\end{array}$ & $\begin{array}{l}\text { Mínimo } \\
(\mathrm{cm})\end{array}$ & $\begin{array}{l}\text { Média } \pm \text { d.p. } \\
\quad\left(\mathrm{cm} \mathrm{ano}^{-1}\right)\end{array}$ & $\begin{array}{l}\text { Máximo } \\
(\mathrm{cm} \text { ano-1) }\end{array}$ & $\begin{array}{l}\text { Mínimo } \\
(\mathrm{cm} \text { ano-1) }\end{array}$ \\
\hline Roçado $(n=22)$ & $1.095 \pm 201,2^{\mathrm{a}}$ & $1.389,0$ & 484,0 & $182,6 \pm 33,5$ & 231,5 & 80,7 \\
\hline Capoeira $(\mathrm{n}=17)$ & $129,5 \pm 107,4^{b}$ & 378,0 & 0,0 & $21,6 \pm 17,9$ & 63,0 & 0,0 \\
\hline Castanhal $(\mathrm{n}=5)$ & $28,0 \pm 58,9^{b}$ & 112,0 & 0,0 & $4,7 \pm 9,8$ & 18,7 & 0,0 \\
\hline \multicolumn{7}{|c|}{ Crescimento em diâmetro } \\
\hline & \multicolumn{3}{|c|}{ Incremento Corrente (6 anos) } & \multicolumn{3}{|c|}{ Incremento Médio Anual } \\
\hline Tratamento & $\begin{array}{l}\text { Média } \pm \text { d.p. } \\
\qquad(\mathrm{cm})\end{array}$ & $\begin{array}{l}\text { Máximo } \\
(\mathrm{cm})\end{array}$ & $\begin{array}{l}\text { Mínimo } \\
(\mathrm{cm})\end{array}$ & $\begin{array}{l}\text { Média } \pm \text { d.p. } \\
\left(\mathrm{cm} \mathrm{ano}^{-1}\right)\end{array}$ & $\begin{array}{l}\text { Máximo } \\
(\mathrm{cm} \text { ano-1) }\end{array}$ & $\begin{array}{l}\text { Mínimo } \\
(\mathrm{cm} \text { ano-1) }\end{array}$ \\
\hline Roçado (n = 22) & $14,50 \pm 6,84^{a}$ & 37,00 & 2,00 & $2,05 \pm 0,53$ & 2,9 & 0,6 \\
\hline Capoeira $(n=17)$ & $1,84 \pm 0,97^{b}$ & 3,90 & 0,60 & $0,31 \pm 0,16$ & 0,65 & 0,10 \\
\hline Castanhal $(\mathrm{n}=5)$ & $0,60 \pm 0,41^{b}$ & 1,30 & 0,30 & $0,10 \pm 0,07$ & 0,22 & 0,05 \\
\hline
\end{tabular}

Tabela 4. Incrementos médios anuais em altura (IMA $)$ e diâmetro (IMA $\left.\mathrm{A}_{\mathrm{d}}\right)$ por anos de plantação. As letras a, b e c em sobrescrito revelam diferenças significativas entre IMA e/ou IMA $A_{d}$, ANOVA e comparações das médias por teste de Tukey.

\begin{tabular}{|c|c|c|c|c|c|c|}
\hline & $\begin{array}{c}\text { IMA }_{h} 1^{\circ} \text { ano } \\
(\mathrm{cm})\end{array}$ & $\begin{array}{c}\text { IMA }_{h} 2^{\circ} \text { ano } \\
(\mathrm{cm})\end{array}$ & $\begin{array}{c}\operatorname{IMA}_{h} 3^{\circ} \text { ano } \\
(\mathrm{cm})\end{array}$ & $\begin{array}{c}\text { IMA }_{h} 4^{\circ} \text { ano } \\
(\mathrm{cm})\end{array}$ & $\begin{array}{c}\text { IMA }_{h} 5^{\circ} \text { ano } \\
(\mathrm{cm})\end{array}$ & $\begin{array}{c}\operatorname{IMA}_{\mathrm{h}} 6^{\circ} \text { ano } \\
(\mathrm{cm})\end{array}$ \\
\hline Roçado & $65,2^{\mathrm{a}}$ & $196,9^{b}$ & $305,5^{c}$ & $154,1^{b}$ & $192,9^{b}$ & $177,4^{b}$ \\
\hline Capoeira & $6,2^{\mathrm{a}}$ & $16,6^{a, b}$ & $29,8^{\mathrm{b}, \mathrm{c}}$ & $14,9^{a, b}$ & $40,2^{c}$ & $21,8^{a, b, c}$ \\
\hline \multirow[t]{2}{*}{ Castanhal } & 4,0 & 0,0 & 3,8 & 0,0 & 11,8 & 15,6 \\
\hline & $\begin{array}{c}\operatorname{IMA}_{d} 1^{\circ} \text { ano } \\
(\mathrm{cm})\end{array}$ & $\begin{array}{l}\text { IMA }_{d} 2^{\circ} \text { ano } \\
(\mathrm{cm})\end{array}$ & $\begin{array}{c}\operatorname{IMA}_{d} 3^{\circ} \text { ano } \\
(\mathrm{cm})\end{array}$ & $\begin{array}{c}\mathrm{IMA}_{d} 4^{\circ} \text { ano } \\
(\mathrm{cm})\end{array}$ & $\begin{array}{l}\text { IMA }_{d} 5^{\circ} \text { ano } \\
(\mathrm{cm})\end{array}$ & $\begin{array}{c}\operatorname{IMA}_{d} 6^{\circ} \text { ano } \\
(\mathrm{cm})\end{array}$ \\
\hline Roçado & $2,1^{a}$ & $2,9^{a, b}$ & $3,6^{\mathrm{b}}$ & $2,0^{\mathrm{a}}$ & $2,8^{a, b}$ & $2,3^{a}$ \\
\hline Capoeira & $0,86^{a}$ & $0,13^{b}$ & $0,39 c$ & $0,07^{b}$ & $0,16^{b}$ & $0,23^{b, c}$ \\
\hline Castanhal & $0,50^{\mathrm{a}}$ & $0,10^{b}$ & $0,00^{b}$ & $0,00^{b}$ & $0,00^{b}$ & $0,00^{b}$ \\
\hline
\end{tabular}


e o menor no quarto ano $\left(\mathrm{IMA}_{\mathrm{d}}=2,0 \mathrm{~cm}\right)$. Aplicado o teste ANOVA para comparação do IMA ${ }_{d}$ por intervalos anuais, o terceiro ano obteve os valores significativamente mais elevados quando comparado com os outros períodos.

No tratamento de capoeira, o crescimento em altura foi maior no quinto ano (IMA $=40,2 \mathrm{~cm})$ e menor no primeiro (IMA $=6,2 \mathrm{~cm})$, havendo diferenças significativas entre alguns intervalos anuais, conforme se pode observar na Tabela 4 (ANOVA, $p=0,045$ ). Em relação ao crescimento anual em diâmetro, os períodos com maiores valores médios foram o primeiro ano $\left(\mathrm{IMA}_{\mathrm{d}}=0,86 \mathrm{~cm}\right)$ e o terceiro ano $\left(\mathrm{IMA}_{\mathrm{d}}=0,39\right.$ $\mathrm{cm}$ ). Os anos com crescimento menor foram o quarto (IMA $=0,07 \mathrm{~cm})$ e o segundo $\left(\mathrm{IMA}_{\mathrm{d}}=0,13\right)$. Aplicando ANOVA ( $p<0,0001)$ e comparando as médias por duplas (teste de Tukey), o crescimento no primeiro ano de plantio foi significativamente mais alto do que nos anos restantes (Figura 4, Tabela 4).

As mudas sobreviventes restantes localizadas nas parcelas de sub-bosque de castanhais tiveram crescimento em altura muito baixo (IMA $=4,7 \mathrm{~cm}$, Tabela 3$)$, e por dois anos o crescimento foi nulo (segundo e quarto anos, Tabela 4). Os anos com maior crescimento em altura foram os dois últimos (quinto, IMA $=11,8 \mathrm{~cm}$, e sexto, $I_{\mathrm{h}} \mathrm{A}_{\mathrm{h}}=$ 15,6 cm; Figura 3, Tabela 4). Neste tratamento, as diferenças de crescimento anuais em altura não foram significativas. $\bigcirc$ crescimento em diâmetro foi nulo a partir do terceiro ano, havendo diferenças significativas entre o primeiro ano $\left(I M A_{d}\right.$ $=0,5 \mathrm{~cm}$ ) e os anos restantes (Figura 4, Tabela 4).

\section{DISCUSSÃO}

\section{SOBREVIVÊNCIA}

A sobrevivência das mudas de castanheira nos plantios de Trombetas após seis anos de plantação foi alta nos tratamentos de roçado (89,6\%) e de capoeira (77\%), e extremamente baixa no tratamento de sub-bosque de castanhais $(20,8 \%)$. Este último resultado foi significativamente diferente em relação ao observado no período monitorado anteriormente (dois anos de plantação, Scoles et al., 2011), devido à expressiva mortalidade de mudas plantadas no sub-bosque de castanhais a partir do terceiro ano de vida (Figura 2).

Excluindo o tratamento de sub-bosque de castanhais, as baixas taxas de mortalidade observadas nos plantios de Trombetas, se comparadas com as de outros estudos experimentais de cultivo de castanheiras, se devem a fatores estritamente metodológicos. Nos experimentos realizados no estado do Acre, em áreas de pastagem (Kainer et al., 1998) ou em áreas de exploração madeireira (Oliveira, 2000), assim como na Bolívia, em clareiras florestais de diferentes dimensões (Peña-Claros et al., 2002), usaram-se mudas com alturas que variaram, dependendo do experimento, entre 7 a $23 \mathrm{~cm}$, tamanhos extremamente vulneráveis a ataques de animais pela presença do hipocotiledone na base da plântula (Oliveira, 2000; Zuidema, 2003). No presente estudo, em contraste, foram escolhidas mudas com tamanhos maiores (alturas entre 80-120 cm), sem presença de hipocotiledone. Nesse caso, conforme foi observado também na Bolívia por Zuidema e Boot (2002), as chances de sobrevivência são mais altas, pelo menos nos dois primeiros anos de vida em qualquer situação luminosa (Scoles et al., 2011). Para idades mais avançadas, os altos índices de sobrevivência das plantas de castanheira se confirmam unicamente para aquelas que permanecem em condições de alta ou média luminosidade. Quando se compara a sobrevivência de castanheiras nas parcelas de roçado do plantio de Trombetas com outras experiências de plantações silviculturais (Tabela 5), este estudo reafirma a baixíssima taxa de mortalidade da espécie em plantios localizados em áreas limpas (100\% de luz).

A novidade deste trabalho foi a brusca queda do índice de sobrevivência nas parcelas de alto sombreamento (subbosque de castanhais) a partir do terceiro ano, o que revela que os ambientes altamente sombreados são prejudiciais para um bom desempenho das mudas de castanheira, comprometendo a sobrevivência das plântulas a médio ou longo prazo. No trabalho experimental realizado na Bolívia, a sobrevivência das mudas também foi menor no tratamento de alto sombreamento em comparação com os tratamentos com maior intensidade de luz, mas ainda assim as diferenças 
Tabela 5. Desempenho, sobrevivência e espaçamento da castanheira em diferentes plantações experimentais na região amazônica. Fontes: ${ }^{1}=$ Costa et al. (2009), ${ }^{2}=$ Fernandes \&Alencar (1993), ${ }^{3}=$ Souza et al. (2008), ${ }^{4}=$ Soares et al. (2004), ${ }^{5}=$ Tonini et al. $(2005),{ }^{6}=$ Vieira et al. $($ (1998).

\begin{tabular}{c|c|c|c|c|c|c}
\hline Localidade & $\begin{array}{c}\text { Tipo de } \\
\text { plantação }\end{array}$ & $\begin{array}{c}\text { Espaçamento } \\
(\mathrm{m})\end{array}$ & $\begin{array}{c}\text { Idade } \\
(\text { anos })\end{array}$ & $\begin{array}{c}\text { Sobrevivência } \\
(\%)\end{array}$ & $I_{\mathrm{IMA}}(\mathrm{m})$ & $\mathrm{IMA}_{\mathrm{d}}(\mathrm{cm})$ \\
\hline Manaus - AM (BR-174) & Consórcio SAF & $12 \times 12$ & 12 & 78 & 1,7 & 3,2 \\
\hline Manaus - AM (BR-174) & Plantio único & $3 \times 3$ & 10 & 69,4 & 1,5 & 1,4 \\
\hline Manaus - AM (AM-010) & Plantio único & $3 \times 3$ & 11 & 52,8 & 1,3 & 1,2 \\
\hline Oriximiná - PA (Trombetas) & Plantio único & $10 \times 10$ & 6 & 100 & 1,9 & 2,1 \\
\hline Manacapuru - AM & Consórcio SAF & $10 \times 20$ & 10 & 57 & 1,3 & 3,1 \\
\hline Cantá - RR & Plantio único & $2,5 \times 2$ & 7 & - & 1,9 & 1,6 \\
\hline Machadinho d'Oeste $-\mathrm{RO}^{6}$ & Consórcio SAF & $12 \times 12$ & 13 & 89,6 & 2,2 & 3,2 \\
\hline Machadinho d'Oeste $-\mathrm{RO}^{6}$ & Plantio único & $3 \times 3$ & 13 & 95,4 & 2,1 & 3,1 \\
\hline
\end{tabular}

não foram tão expressivas como nos plantios de Trombetas (Peña-Claros et al., 2002). Contudo, a baixa sobrevivência das mudas de castanheira nas áreas experimentais do sub-bosque explicaria as menores taxas de recrutamento das florestas primárias em relação às secundárias (Cotta et al., 2008), assim como as dificuldades de encontrar regeneração natural da espécie nas florestas maduras com alto sombreamento (Myers et al., 2000; Scoles \& Gribel, 2012). Tal fato explica também que a baixa taxa de regeneração, nesse caso, não pode ser atribuída ao excesso de coleta de sementes pelas populações locais.

\section{REBROTAÇÃO}

Este estudo comprovou a alta capacidade de rebrotação de castanheira após perturbações de diferente natureza, inclusive por fogo. As circunstâncias temporais e ambientais permitiram observar como as mudas queimadas em duas parcelas de roçado não somente sobreviveram em sua maioria (90\%), mas inclusive rebrotaram com vigor, apresentando IMA mais alto durante o período posterior à perturbação (2010-2013) em relação ao período anterior (2007-2009). Com esses resultados, pode-se afirmar que, dentro de certos limites, a castanheira é uma árvore resiliente ao fogo e apoia a tese de que é indicadora de distúrbios antrópicos pretéritos e/ou recentes (Balée \& Campbell, 1990; Scoles \& Gribel, 2011). Outro aspecto relevante nas parcelas queimadas foi a aparição de mais de um caule na maioria de mudas rebrotadas.
Esse fenômeno é coincidente com observações feitas em castanhais manejados e/ou humanizados (Lago Sapucuá, em Oriximiná, e Lago Capanã Grande, em Manicoré, Ricardo Scoles et al., comunicação pessoal), com a presença não rara de árvores com caules bifurcados ou trifurcados, muito provavelmente oriundos de rebrotações causadas por distúrbios relacionados com o fogo, pois esses indivíduos localizam-se em áreas de alta perambulação humana e próximas a residências, e/ou em áreas de lavoura.

\section{CRESCIMENTO DAS MUDAS}

O crescimento em altura e diâmetro das mudas de castanheira plantadas na região do rio Trombetas, ao longo de seis anos, dependeu, em grande parte, do grau de exposição à luz a que foram submetidas. Conforme o trabalho anterior na área já tinha revelado (Scoles et al., 2011), o tratamento de roçado teve alto desempenho das mudas, significativamente maior que os outros dois tratamentos, sendo a intensidade de luz a principal variável explicativa.

Em geral, os solos das plantações de Trombetas caracterizaram-se por serem muito ácidos ( $\mathrm{pH}<4,5)$, com baixa capacidade de troca de cátions $\left(\right.$ CTC $_{t}<$ 2,0 $\mathrm{cmol}_{c} \mathrm{~kg}^{-1}$ ) e baixa percentagem de matéria orgânica (entre 1,8 e 2,4\%), ricos em ferro e alumínio, e pobres na maioria de nutrientes analisados (Lopes \& Guilherme, 1992), seguindo as características edafológicas dos solos de

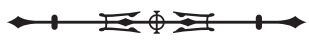


terra firme da região amazônica: alta acidez, intemperismo intenso, déficit de fertilidade, baixa capacidade de troca catiônica e alta saturação de alumínio (Cochrane \& Sánchez, 1982; Schubart et al., 1984; Vieira \& Santos, 1987). As provas estatísticas de comparação entre amostras de solo evidenciaram diferenças significativas entre os tratamentos de sub-bosque de castanhais e os outros dois tratamentos para dois micronutrientes (manganês e cálcio). As diferenças também foram relevantes na saturação por bases (V\%), já que os resultados percentuais revelam caráter distrófico no sub-bosque de castanhais (V\% = 23\%), em contraposição às propriedades eutróficas dos solos de capoeira $(\mathrm{V} \%=$ $59 \%$ ) e roçado (V\% = 53\%). Ainda que essas diferenças de fertilidade possam explicar o pior desempenho do castanhal em relação aos outros dois tratamentos, elas não conseguem responder por que o desempenho médio das mudas da capoeira e roçado são tão díspares, apesar da grande similaridade nas propriedades químicas dos seus solos. Dessa forma, reafirmando as conclusões de Scoles et al. (2011), este trabalho evidencia que as diferenças de crescimento em altura e diâmetro entre roçado e os outros dois tratamentos somente podem ser explicadas pela exposição direta das mudas ao sol, muito mais favorável para um melhor desempenho das mudas de castanheira.

Essa situação é coincidente com a de outro trabalho experimental desenvolvido em florestas secundárias da Bolívia, onde, após quatro anos de plantio, o crescimento em altura das mudas de castanheira aumentou com o tamanho da clareira (Peña-Claros et al., 2002). Ainda assim, o desempenho das mudas plantadas em áreas florestais sombreadas na pesquisa da Bolívia (IMA $A_{h}=17 \mathrm{~cm}$ ) foi mais alto do que o observado neste estudo $\left(n=5, I M A_{h}=\right.$ $4,7 \mathrm{~cm}$ ). Por outro lado, nas condições de luminosidade plena, o desempenho das mudas da pesquisa na Bolívia foi notavelmente mais baixo $\left(\mathrm{IMA}_{\mathrm{h}}=96,5 \mathrm{~cm}\right)$ do que em Trombetas $\left(\mathrm{IMA}_{h}{ }_{\mathrm{h}}^{\text {anos }}=179,8 \mathrm{~cm} ; \mathrm{IMA}_{h}{ }^{6}\right.$ anos $\left.=182,6 \mathrm{~cm}\right)$.

Ambos os trabalhos mostram resultados um pouco diferentes daqueles obtidos por Kainer et al. (1998) no Acre, em um outro estudo de desempenho de mudas de castanheira em três diferentes ambientes experimentais por dois anos de duração. Nesse caso, as mudas com um crescimento em altura e diâmetro significativamente mais alto se localizaram no tratamento de capoeira (64\% de luz incidente), em detrimento dos tratamentos com menor (clareira florestal, 21,5\% de luz) e maior (pastagens, 71\% de luz) exposição luminosa. A possível discordância de resultados é relativa, já que, no experimento do Acre, as diferenças de crescimento das plântulas entre ambos os tratamentos (na capoeira cresceram duas vezes mais) podem ser explicadas pela maior compactação do solo e menor teor de nutrientes (cálcio, potássio, magnésio e fósforo extraído) das áreas de pastagens, pois a entrada de luz não foi significativamente diferente entre as áreas de capoeira e pastagem (Kainer et al., 1998).

Este trabalho de seis anos de duração confirma numerosos estudos de plantios silviculturais experimentais, que evidenciam que a castanheira, por sua alta taxa de sobrevivência, tolerância a solos degradados, excelente desempenho em condições de alta luminosidade e resistência a secas prolongadas, é uma espécie promissora para uso em reflorestamento de áreas abertas na Amazônia (Fernandes \& Alencar, 1993; Yared et al., 1993; Salomão et al., 2006; Souza et al., 2008; Costa et al., 2009; Ferreira et al., 2012). Além disso, a castanheira produz grande quantidade de matéria orgânica morta (folhas secas), favorecendo a ciclagem de nutrientes dos solos via liteira (Schroth et al., 2001; Silva et al., 2008; Costa et al., 2009). Não obstante todas essas qualidades positivas, continua sendo baixo o uso dessa e de outras espécies nativas nos plantios de produção na região da Amazônia Legal, dominados por espécies exóticas, como pinheiros, eucaliptos e tecas (Pereira et al., 2010).

Comparando o desempenho das mudas de castanheira nos plantios experimentais de Trombetas em situação de alta luminosidade (tratamento de roçado) com outras plantações experimentais em várias regiões da Amazônia (Tabela 5), comprova-se que, após seis anos da plantação, o desempenho em altura das mudas é expressivo (IMA $A_{h}=1,9 m$ ), unicamente superado 
pela experiência de Machadinho d'Oeste, em Rondônia $\left(\operatorname{IMA}_{\mathrm{h}}=2,2 \mathrm{~m}\right) . \mathrm{O}$ crescimento em diâmetro das mudas plantadas nos roçados de Trombetas $\left(\mathrm{IMA}_{\mathrm{d}}=2,1 \mathrm{~cm}\right)$ fica em uma situação intermediária entre as experiências com desempenhos modestos (IMA $<1,6 \mathrm{~cm}$ ) e as plantações com crescimentos maiores (IMA $\mathrm{d}_{\mathrm{d}}>3 \mathrm{~cm}$ ).

Analisando a dinâmica do crescimento anual das mudas plantadas em Trombetas, no tratamento de roçado observouse um aumento significativo do desempenho em altura e diâmetro no segundo e terceiro ano (especialmente neste último), estabilizando-se a partir do quarto ano. Na capoeira, essa tendência foi observada unicamente para os incrementos anuais em altura, com a particularidade de ser o quinto ano o de maior IMA, podendo-se prever uma tendência ascendente de desempenho nos últimos períodos, tendência essa que poderá ser ou não confirmada nos próximos anos (Figura 3). Quanto ao diâmetro, o IMA significativamente mais alto ocorreu no primeiro ano da plantação, provavelmente como forma de compensação do baixo incremento em altura, não obstante o aporte inicial de adubação. Nos dois anos restantes, as diferenças não foram significativas, à exceção do terceiro ano, que apresentou um IMA superior aos dos anos antecedentes e subsequentes. No tratamento de sub-bosque de castanhais, os incrementos anuais foram praticamente insignificantes, sendo somente apreciável o primeiro ano da plantação, seguramente pelo efeito da adubação inicial.

\section{CONCLUSÃO}

O trabalho de monitoramento dos plantios experimentais na região do rio Trombetas, em diferentes condições ambientais, revelou um desempenho em crescimento e altura significativamente mais alto das mudas plantadas em áreas abertas (roçados de lavoura de mandioca) do que o das localizadas em áreas de sombreamento alto ou intermediário (sub-bosque de castanhais e capoeiras jovens). Não há dúvida de que o principal fator desencadeante que explica essa diferença é a exposição à luz solar (mais alta no roçado), confirmando, assim, que a castanheira, não obstante ser uma espécie dominante e emergente nas florestas maduras onde ela ocorre, é dependente de luz para o seu desempenho juvenil. De igual forma, o trabalho aponta para uma alta capacidade de rebrotação da espécie após perturbação por fogo, desde que se mantenham as condições ambientais de alta luminosidade. Após seis anos de plantio, os índices de sobrevivência se mantiveram altos nos tratamentos de roçado e capoeira, diferenciando-se ambos da situação do sub-bosque de castanhais, que, em contraste, teve altíssimas taxas de mortalidade a partir do terceiro ano da plantação, questionando, assim, a possibilidade de sobrevivência das mudas dessa espécie a longo prazo em condições de alto sombreamento. $\bigcirc$ estudo reafirma a necessidade de serem utilizadas mudas de castanheira com alturas superiores a $80 \mathrm{~cm}$, sem hipocotiledone, em todas as experiências de plantação para que se garanta uma maior taxa de sobrevivência das mudas selecionadas. Por último, a castanheira, árvore nativa e de grande importância socioeconômica na região amazônica, tem altíssimo potencial silvicultural para programas de reflorestamento, recuperação de ambientes degradados e enriquecimento de capoeiras, desde que sejam adotados os devidos cuidados para manter as mudas juvenis expostas à luz solar direta.

\section{AGRADECIMENTOS}

Agradecemos o apoio financeiro e logístico do Programa de Áreas Protegidas da Amazônia (ARPA), Instituto Chico Mendes de Conservação da Biodiversidade (ICMBio) do Porto Trombetas, Conselho Nacional de Desenvolvimento Científico e Tecnológico (CNPq) e Programa Beca, do Instituto Internacional de Educação do Brasil. Agradecemos também ao Projeto 'Banco do Germoplasma da Castanheira', do Instituto Nacional de Pesquisas da Amazônia/Mineração Rio do Norte/Instituto Brasileiro do Meio Ambiente e dos Recursos Naturais Renováveis (INPA/MRN/IBAMA), pelo gentil fornecimento de mudas de Bertholletia excelsa, produzidas no viveiro da MRN do Porto Trombetas. Somos gratos também ao Laboratório Temático de Plantas e Solos do Instituto Nacional de Pesquisas da Amazônia, pela execução das 
análises físico-químicas das amostras de solo coletadas. Os mais sinceros agradecimentos a todas as famílias quilombolas da comunidade de Tapagem, à equipe humana do Instituto Chico Mendes de Conservação da Biodiversidade do Porto Trombetas e aos funcionários do Viveiro da MRN em Porto Trombetas, pela ajuda desinteressada neste trabalho. Com especial ênfase, agradecemos a Dometilo Xavier, Manoel Dileno, Josenildo, Junho, Raimundo, Cleunildo, Edelson, Vivaldo, João Raimundo e Josimar, moradores da Tapagem e de outras comunidades vizinhas, pela participação direta na plantação e na coleta de dados de campo ao longo dos seis anos de trabalho.

\section{REFERÊNCIAS}

ACEVEDO MARIN, R. E. \& E. M. R. CASTRO, 1998. Negros do Trombetas: guardiães de matas e rios: 1-262. CEJUP, Belém.

ANDERSON, A. B., 1994. Extrativismo vegetal e reservas extrativistas. In: A. B. ANDERSON, M. H. ALEGRETTI, S. SCHWARTZMAN, M. MENEZES, R. MATTOSOS, V. FLEISCHFRESSER, D. FELIPPE, V. WAWZYNIAK \& R. ARNT (Orgs.): O destino da floresta: reservas extrativistas e desenvolvimento sustentável na Amazônia: 227-245. RelumeDumará, Rio de Janeiro.

BALÉE, W. \& D. G. CAMPBELL, 1990. Evidence for the successional status of liana forest (Xingu river basin, Amazonian Brazil). Biotropica 22(1): 36-47.

BENTES, R. S., R. A. MARÍN \& M. F. EMMI, 1988. Os cemitérios das castanheiras do Tocantins. Pará Desenvolvimento 23: 18-23.

CLAY, J. W., 1997. Brazil nuts: the use of a keystone species for conservation and development. In: C. H. FREESE (Ed.): Harvesting wild species: implications for biodiversity conservation: 246-282. The Johns Hopkins University Press, Baltimore.

CLEMENT, C. R., 2006. A lógica do mercado e o futuro da produção extrativista. Simpósio Brasileiro de Etnobiologia e Etnoecologia 6: 5 .

COCHRANE, T. T. \& P. A. SÁNCHEZ, 1982. Recursos de tierras, suelos y su manejo en la región amazónica: informe acerca del estado de conocimientos. In: S. B. HECHT (Ed.): Amazonia: investigación sobre agricultura y uso de tierras: 141-218. Centro Internacional de Agricultura Tropical, Cali.

COSTA, J. R., A. B. C. CASTRO, E. V. WANDELLI, S. C. T. CORAL \& S. A. G. SOUZA, 2009. Aspectos silviculturais da castanha-dobrasil (Bertholletia excelsa) em sistemas agroflorestais na Amazônia Central. Acta Amazonica 39(4): 843-850.
COTTA, J. N., K. A. KAINER, L. H. O. WADT \& C. L. STAUDHAMMER, 2008. Shifting cultivation effects on Brazil nut (Bertholletia excelsa) regeneration. Forest Ecology and Management 256(1-2): 28-35.

EMPRESA BRASILEIRA DE PESQUISA AGROPECUÁRIA (EMBRAPA), 1997. Manual de métodos de análise de solo: 1-212. EMBRAPA-CNPS, Rio de Janeiro.

EMPRESA BRASILEIRA DE PESQUISA AGROPECUÁRIA (EMBRAPA), 1999. Manual de análises químicas de solos, plantas e fertilizantes: 1-370. EMBRAPA Solos, Rio de Janeiro.

EMPRESA BRASILEIRA DE PESQUISA AGROPECUÁRIA (EMBRAPA), 2006. Sistema brasileiro de classificação de solos: 1-306. EMBRAPA-CNPS, Rio de Janeiro.

FERNANDES, N. P. \& J. C. ALENCAR, 1993. Desenvolvimento de árvores nativas em ensaios de espécies. 4. Castanha-do-brasil (Bertholletia excelsa H. B. K.), dez anos após o plantio. Acta Amazonica 23(2-3): 191-198.

FERREIRA, M. J., J. F. C. GONÇALVES \& J. B. S. FERRAZ, 2012. Crescimento e eficiência do uso da água de plantas jovens de castanheira-da-amazônia em área degradada e submetidas à adubação. Ciência Florestal 22(2): 393-401.

HOMMA, A. K. O., 1993. Extrativismo vegetal na Amazônia: limites e oportunidades: 1-202. EMBRAPA-SPI, Brasília.

HOMMA, A. K. O., R. A. CARVALHO, C. A. P. FERREIRA \& J. D. B. NASCIMENTO JÚNIOR, 2000. A destruição de recursos naturais: o caso da castanha-do-pará no sudeste paraense: 1-74. EMBRAPA Amazônia Oriental (Documentos, 32), Belém.

INSTITUTO BRASILEIRO DE GEOGRAFIA E ESTATÍSTICA (IBGE), 2011. Produção da extração vegetal e da silvicultura. Disponível em: <http://www.ibge.gov.br/home/estatistica/economia/pevs/2011/ default.shtm>. Acesso em: 15 setembro 2013.

INSTITUTO BRASILEIRO DO MEIO AMBIENTE E DOS RECURSOS NATURAIS RENOVÁVEIS/MINERAÇÃO RIO DO NORTE (IBAMA/MRN), 2001. Plano de manejo da Floresta Nacional de Saracá Taquera, estado do Pará, Brasil: 1-708. IBAMA STCP/MRN, Curitiba.

INSTITUTO DE DESENVOLVIMENTO ECONÔMICO, SOCIAL E AMBIENTAL DO PARÁ (IDESP), 2011. Cadeias de comercialização de produtos florestais não madeireiros na Região de Integração Baixo Amazonas, estado do Pará: relatório técnico: 1-221. IDESP, Belém.

INSTITUTO NACIONAL DE PESQUISAS ESPACIAIS (INPE), 2014. Sistema Integrado de Dados Ambientais. Plataforma de Coleta de Dados. Disponível em: < http://sinda.crn2.inpe.br/PCD/ metadados.jsp?uf $=13 \& i d=32587 \&$ tipo $=$ MET\&idVariavel $=4 \& \mathrm{dia}=$ $30 \&$ mes $=11 \&$ ano $=2013 \&$ Submit $2 \cdot x=19 \&$ Submit $2 \cdot y=6>$. Acesso em: 7 agosto 2014

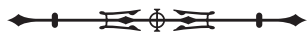


KAINER, K. A., M. L. DURYEA, N. C. MACEDO \& K. WILLIAMS, 1998. Brazil nut seedling establishment and autecology in extractive reserves of Acre, Brazil. Ecological Applications 8(2): 397-410.

LILLIEFORS, H. W., 1967. On the Kolmogorov-Smirnov test for normality with mean and variance unknown. Journal of the American Statistical Association 62(318): 399-402.

LOPES, A. S. \& L. R. G. GUILHERME, 1992. Interpretação e análise do solo: conceitos e aplicações: 1-48. Associação Nacional para Difusão de Adubos (Boletim Técnico, 2), São Paulo.

MORI, S. A., 1992. The Brazil nut industry - past, present, and future. In: M. PLOTKIN \& L. FAMOLARE (Eds.): Sustainable harvest and marketing of rain forest products: 241-251. Island Press, Washington.

MORI, S. A. \& G. T. PRANCE, 1990. Taxonomy, ecology, and economic botany of the Brazil nut (Bertholletia excelsa Humb. \& Bonpl.: Lecythidaceae): 130-150. The New York Botanical Garden (Advances in Economic Botany, 8), New York.

MÜLLER, C. H., I. A. RODRIGUES, A. A. MÜLLER \& N. R. M. MÜLLER, 1980. Castanha-do-brasil: resultados de pesquisa: 1-25. EMBRAPA, Centro de Pesquisa Agropecuária do Trópico Úmido (Miscelânea, 2), Belém.

MYERS, G. P., A. C. NEWTON \& O. MELGAREjO, 2000. The influence of canopy gap size on natural regeneration of Brazil nut (Bertholletia excelsa) in Bolivia. Forest Ecology and Management 127(1-3): 119-128.

OLIVEIRA, M. V. N., 2000. Artificial regeneration in gaps and skidding trails after mechanized forest exploitation in Acre, Brazil. Forest Ecology and Management 127(1-3): 67-76.

ORTIZ, E. G., 2002. Brazil nut (Bertholletia excelsa). In: P. SHANLEY, A. R. PIERCE, S. A. LAIRD \& A. GUILLÉN (Eds.): Tapping the green market: certification and management of non-timber forest products: 61-74. Earthscan Publications Ltd., London.

PAIVA, P. M., M. C. GUEDES \& C. FUNI, 2011. Brazil nut conservation through shifting cultivation. Forest Ecology and Management 261(3): 508-514.

PEÑA-CLAROS, M., R. G. A. BOOT, J. DORADO-LORA \& A. ZONTA, 2002. Enrichment planting of Bertholletia excelsa in secondary forest in the Bolivian Amazon: effect of cutting line width on survival, growth and crown traits. Forest Ecology and Management 161(1-3): 159-168.

PEREIRA, H. S., 1994. Manejo agroflorestal da castanheira (Bertholletia excelsa H. B. K.) na região do Lago do Tefé (AM). Revista da Universidade do Amazonas. Série Ciências Agrárias 3(1): 11-32.

PEREIRA, D., D. SANTOS, M. VEDOVETO, J. GUIMARÃES \& A. VERÍSSIMO, 2010. Fatos florestais da Amazônia: 1-124. IMAZON, Belém.
RIBEIRO, M. B. N., A. JEROZOLIMSKI, P. ROBERT, N. V. SALLES, B. KAYAPÓ, T. P. PIMENTEL \& W. E. MAGNUSSON, 2014. Anthropogenic landscape in Southeastern Amazonia: contemporary impacts of low-intensity harvesting and dispersal of Brazil nuts by the Kayapó indigenous people. PLoS ONE 9(7): e102187.

SALOMÃO, R. P., 1991. Estrutura e densidade de Bertholletia excelsa H. \& B. ('Castanheira') nas regiões de Carajás e Marabá, estado do Pará. Boletim do Museu Paraense Emílio Goeldi, série Botânica 7(1): 47-68.

SALOMÃO, R. P., N. A. ROSA, A. CASTILHO \& K. A. C. MORAIS, 2006. Castanheira-do-brasil recuperando áreas degradadas e provendo alimento e renda para comunidades da Amazônia Setentrional. Boletim do Museu Paraense Emílio Goeldi. Ciências Naturais 1(2): 65-78.

SCHROTH, G., I. LEHMANN, M. R. L. RODRIGUES, E. BARROS \& J. L. V. MACEDO, 2001. Plant-soil interactions in multistrata agroforestry in the humid tropics. Agroforestry Systems 53(2): 85-102.

SCHUBART, H. O. R., W. FRANKEN \& F. J. LUIZÃO, 1984. Uma floresta sobre solos pobres. Ciência Hoje 2(10): 26-32.

SCOLES, R., R. GRIBEL \& G. N. KLEIN, 2011. Crescimento e sobrevivência de castanheira (Bertholletia excelsa Bonpl.) em diferentes condições ambientais na região do rio Trombetas, Oriximiná, Pará. Boletim do Museu Paraense Emílio Goeldi. Ciências Naturais 6(3): 273-293.

SCOLES, R. \& R. GRIBEL, 2011. Population structure of Brazil nut (Bertholletia excelsa, Lecythidaceae) stands in two areas with different occupation histories in the Brazilian Amazon. Human Ecology 39(4): 455-464

SCOLES, R., 2012. Parceria histórica entre a castanheira e as comunidades tradicionais amazônicas. Ver-a-Ciência 2: 18-25.

SCOLES, R. \& R. GRIBEL, 2012. The regeneration of Brazil nut trees in relation to nut harvest intensity in the Trombetas River valley of Northern Amazonia, Brazil. Forest Ecology and Management 265(1): 71-81.

SILVA, P. T. E., S. BRIENZA JÚNIOR, J. A. G. YARED, P. L. C. BARROS \& M. N. M. MACIEL, 2008. Principais espécies florestais utilizadas em sistemas agroflorestais na Amazônia. Revista Ciências Agrárias 49: 127-144.

SOARES, J. E. C., J. VAN LEEUWEN \& J. B. M. GOMES, 2004. O desenvolvimento da castanha-do-brasil (Bertholletia excelsa H. B. K.) em plantios agroflorestais no município de Manacapuru, Amazonas, Brasil. Anais do Congresso Brasileiro de Sistemas Agroflorestais 5: 380-382.

SOUZA, C. R., R. M. B. LIMA, C. P. AZEVEDO \& L. M. B. ROSSI, 2008. Desempenho de espécies florestais para uso múltiplo na Amazônia. Scientia Forestalis 36(77): 7-14.

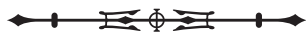


SWAINE, M. D. \& T. C. WHITMORE, 1988. On the definition of ecological species groups in tropical rain forests. Vegetatio 75(1-2): 81-86.

TONINI, H., M. F. ARCO-VERDE \& S. P. P. SÁ, 2005. Dendrometria de espécies nativas em plantios homogêneos no estado de Roraima: andiroba (Carapa guianensis Aubl), castanha-do-brasil (Bertholletia excelsa Bonpl.), ipê-roxo (Tabebuia avellanedae Lorentz ex Griseb) e jatobá (Hymenaea courbaril L.). Acta Amazonica 35(3): 353-362.

TUCK haugAASEN, J. M., T. HAUGAASEN, C. A. PERES, R. GRIBEL \& P. WEGGE, 2010. Seed dispersal of the Brazil nut tree (Bertholletia excelsa) by scatter-hoarding rodents in a central Amazonian forest. Journal of Tropical Ecology 26(3): 251-262.

TUCK hAUGAASEN, J. M., T. HAUGAASEN, C. A. PERES, R. GRIBEL \& P. WEGGE, 2012. Fruit removal and natural seed dispersal of the Brazil nut tree (Bertholletia excelsa) in Central Amazonia, Brazil. Biotropica 44(2): 205-210.
VIEIRA, A. H., M. LOCATELLI \& V. F. SOUZA, 1998. Crescimento de castanha-do-brasil em dois sistemas de cultivo: 1-13. EMBRAPA-CPAF Rondônia (Boletim de Pesquisa, 22), Porto Velho.

VIEIRA, L. S. \& P. C. T. C. SANTOS, 1987. Amazônia, seus solos e outros recursos naturais: 1-416. Editora Agronômica Ceres, São Paulo.

YARED, J. A. G., M. KANASHIRO, L. M. VIANA, T. C. A. CASTRO \& J. R. S. PANTOJA, 1993. Comportamento silvicultural de castanheira (Bertholletia excelsa H. \& B.) em diversos locais da Amazônia. Anais do Congresso Florestal Panamericano 1(2): 416-418.

ZUIDEMA, P. A., 2003. Ecología y manejo del árbol de castaña (Bertholletia excelsa): 1-117. PROMAB (Serie Científica, 6), Riberalta.

ZUIDEMA, P. A. \& R. G. A. BOOT, 2002. Demography of the Brazil nut tree (Bertholletia excelsa) in the Bolivian Amazon: impact of seed extraction on recruitment and population dynamics. Journal of Tropical Ecology 18: 1-31. 